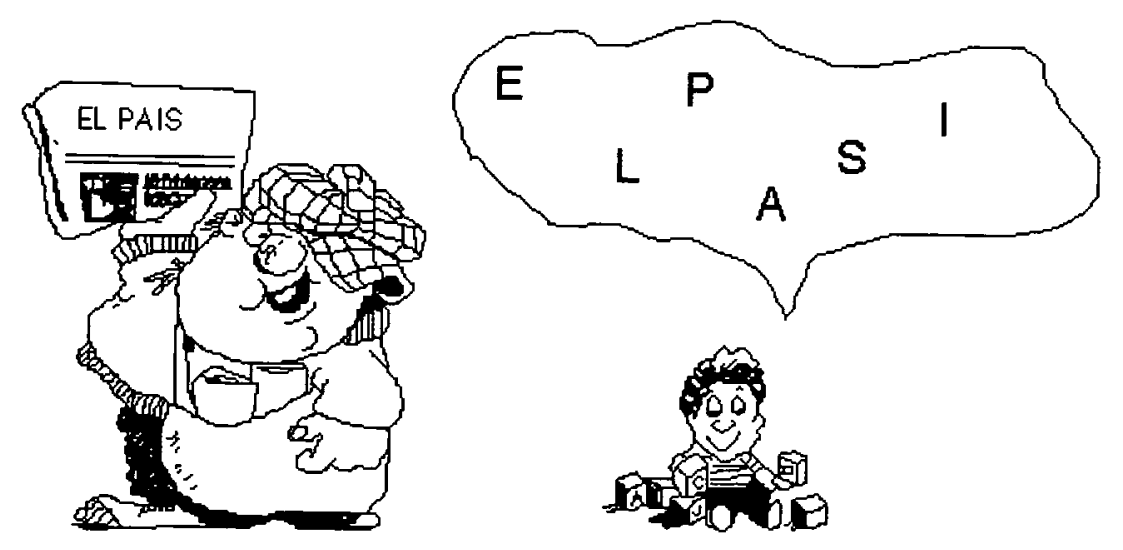




\section{Lenguaje integrado: sus creencias sobre la alfabetización}

\section{Beatriz Martín}
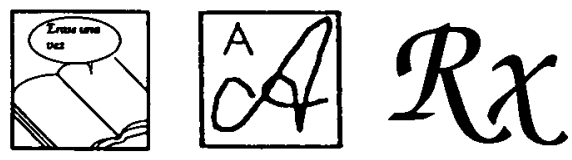

El "lenguaje integrado» se presenta como un sistema alternativo para la enseñanza de la lecto-escritura y, progresivamente, sus postulados se ban ido extendiendo de forma que desde él se trata de fundamentar un sistema de enseñanza-aprendizaje que abarca al conjunto del currículum. ¿Cuáles son esos presupuestos?, ¿qué importancia tiene el lenguaje cuando se adopta esta perspectiva?, ¿cuáles son sus presupuestos acerca de la naturaleza del lenguaje? Estas y otras cuestiones se abordarán en este artículo.

\section{INTRODUCCIÓN}

El lenguaje integrado es un movimiento pedagógico que se presenta como un programa alternativo de alfabetización. Su postulado central es que el lenguaje se debe enseñar de forma global, es decir, con sus sistemas semánticos, sintácticos, lingüísticos y grafo-fonéticos intactos, y en situaciones significativas, en las que el uso del lenguaje tenga un propósito o meta determinada y se vea apoyado por la pragmática, que se compone del contexto situacional en el que se usa el lenguaje, y por el conocimiento previo del alumno activado en dicho contexto (Watson, 1989). Tras este postulado se esconden un conjunto de creencias acerca de la alfabetización que conviene hacer explícita con el fin de analizar su validez. El criterio de validez de las creencias que subyacen a una práctica pedagógica dependen de su acuerdo con los principios evolutivos contrastados experimentalmente acerca de los procesos a los que éstas prácticas van dirigidas. Por lo tanto, en el siguiente artículo nos proponemos llevar a cabo un análisis de las creencias que mantienen los seguidores del lenguaje integrado sobre el proceso de alfabetización y compararlas con otros modelos existentes.

A continuación expondremos algunas corrientes teóricas que han abordado el concepto de alfabetización, para después tratar en profundidad la idea que acepta la filosofía del lenguaje integrado.

\section{ALFABETIZACIÓN: HACIA UNA NUEVA FORMA DE PENSAMIENTO}

La alfabetización se ha convertido en un elemento imprescindible de la cultura occidental. Vivimos en un mundo alfabetizado, en el que la persona que no ha apren- 
dido a leer y a escribir puede muchas veces verse en situaciones embarazosas, ya que nuestro mundo está impregnado del medio impreso en gran cantidad de contextos. Por lo tanto, es de gran importancia definir y comprender qué es la alfabetización, cuáles son sus elementos principales y cuáles son las vías de instrucción más adecuadas para conseguir que el niño entre en el complejo mundo de la lecto-escritura.

Sin embargo, en la práctica educativa subyacen creencias a veces muy distintas en cuanto a qué supone la alfaberización y cuál es su proceso de adquisición. Estas diferencias en las formas de concebir este proceso, lejos de ser intranscendentes, tendrán un efecto contundente en los métodos y técnicas empleadas en el medio educativo para mejorar las habilidades lingüísticas, y su éxito dependerá en gran medida de que las creencias que tenga el maestro acerca del proceso de alfabetización sean las adecuadas, ya que, si estas son infundadas, pueden debilitar más que facilitar el aprendizaje del alumno. Por ello, hay que analizar todas las creencias subyacentes a las prácticas educativas y comprobar si son adecuadas (Harste y Burke, 1989).

Una interesante aportación sobre las distintas formas de entender la alfabetización es la que hace Wells (1987). Este autor propone una taxonomía de cuatro niveles representativo, funcional, informativo y epistémico - derivada de sus observaciones de estas ideas en los profesores, y que representan las distintas definiciones operativas que se plantean en educación acerca de la alfabetización. Las diferencias entre estos cuatro niveles se basan en las distintas formas de considerar las relaciones entre escritura y habla, por una parte, y entre escritura y pensamiento, por otra. En cada una de ellas se pone el acento en distintos procesos en el fenómeno de la adquisición de la lecto-escritura.

Un primer nivel de la alfabetización sería el representativo. Aquí, el énfasis se pone en las características superficiales del código en sí mismo. La alfabetización, en este nivel, consistiría simplemente en la adquisición de las habilidades de codificación y decodificación del lenguaje escrito, cuya única diferencia con el lenguaje oral estaría en el canal de comunicación. Es decir, en este nivel se considera la escritura como una mera transcripción del lenguaje oral a un código distinto al fonológico.

En el segundo nivel, el funcional, el énfasis se pone en los usos del lenguaje escrito en la comunicación interpersonal. Estar alfabetizado supone ser capaz de enfrentarse a las demandas cotidianas que impone el lenguaje escrito en una sociedad dada. Aunque en este nivel se acepte la importancia del nivel representativo, se hace hincapié en que la forma del lenguaje escrito cambia dependiendo del contexto social en que se presenta, por lo que se considera importante instruir al niño en habilidades de lectura y escritura en situaciones diversas y significativas.

El tercer nivel es el informativo, en el cual se destaca la función del lenguaje escrito como transmisor de conocimiento. Se da prioridad a la lectura, siendo la escritura un medio para registrar lo que se ha aprendido y para demostrar este aprendizaje a otros (en un examen, por ejemplo). Se asume que los problemas que pueda tener el sujeto se relacionarán más con el contenido de los textos que con los procesos de interpretación o composición. Por lo tanto, el este nivel, el énfasis se sitúa en la posibilidad que brinda la lectura para acceder al conocimiento.

Por último, el nivel epistémico supera a los anteriores en el sentido de que, además de considerar la alfabetización como un modo distinto de comunicación, se piensa que aporta una nueva forma de pensar, una herramienta para actuar sobre el conocimiento y transformarlo. Para Wells «desde un punto de vista curricular, la alfabetización es tanto una forma de usar el lenguaje como una forma de pensar, y las aptitudes a fomentar son la creatividad, la exploración y la evaluación crítica».

Cada una de estas cuatro formas de entender la alfaberización es importante y aporta algo a la idea de lo que es estar alfabetizado. Los niveles inferiores están incluidos en los superiores, siendo el superior, para Wells, el más adecuado. 
Concebir la alfabetización desde un punto de vista epistémico supone asumir unas relaciones determinadas entre el lenguaje oral, el escrito y el pensamiento.

Wells señala que, a pesar de que no todo uso del lenguaje conduce a una elaboración conceptual compleja, el papel del educador es enseñar al niño a poner su nueva capacidad lingüística, la lecto-escritura, al servicio del pensamiento. Esta capacidad permite al sujeto que la posee implicarse en una actividad mental sostenida y creativa que sólo con el lenguaje oral sería casi imposible. Pero ¿cuáles son las diferencias entre el lenguaje oral y el escrito, que hacen que sea éste último el más adecuado para desenvolvernos en este tipo de actividades? Dos son las principales diferencias que señala este autor, la primera de naturaleza contextual y la segunda dependiente de las características propias del modo de producción. En primer lugar habla de la distancia que se genera entre el escritor y el lector en el medio escrito, a diferencia de la cercanía y la cantidad de claves contextuales y no verbales que impregnan el medio oral. Esto hace que la cantidad de conocimiento compartido entre el transmisor y el receptor sea menor en el medio escrito, y que todo el peso recaiga en lo verbal, en el texto, que debe ser lo suficientemente explícito e independiente de su contexto de origen para que la comunicación tenga éxito. Esta circunstancia supone unas demandas cognitivas ausentes en el modo de expresión oral.

En segundo lugar, Wells señala que una de las características más importantes del medio escrito es el tiempo que se invierte en la producción, lo cual posibilita una elección más precisa de la información que se desea transmitir y de la forma de expresarla. La ausencia de las limitaciones de tiempo que caracterizan el medio oral, debido a la presencia de uno o varios interlocutores y a la necesidad de intercambio de turnos en la conversación, permiten al escritor embarcarse en una tarea de composición en la que seleccionará y refinará sus expresiones para comunicar sus ideas de una forma más precisa.

Estas diferencias suponen que la relación entre pensamiento y lenguaje que se da en la escritura sea distinta a la que se mantiene en un medio conversacional. Según Wells: «...mientras que en la conversación se requiere poco más que la selección de ideas familiares "simbólicamente representadas en los surcos de la expresión habitual", la prosa escrita-al igual que la poesía-implica procesos de composición en los que la experiencia es transformada en un intento de organización y de adecuación a las demandas específicas del texto."(pag.113).

Sin embargo, la adquisición de la alfabetización no sólo se refleja en el medio escrito, sino que los logros cognitivos que supone esta capacidad se reflejarán también en el oral. Citando otra vez a Wells: «En el amplio sentido de la palabra, por lo tanto, alfabetizarse es ser capaz de explorar el amplio potencial simbólico del lenguaje para el pensamiento, tanto en el medio oral como en el escrito.» (pag.114)

Por lo tanto, el modelo inclusivo de la alfabetización de Wells concibe el lenguaje escrito como diferente al oral, no solo en el canal de expresión, sino también en la naturaleza del lenguaje en sí mismo, de modo que la escritura no sería simplemente lenguaje oral transcrito a un código distinto, sino que los procesos de pensamientos ligados a ambos modos serían diferentes. También piensa de esta forma Olson (1993), que rechaza la concepción de la escritura como mera transcripción de lo oral, introducida sobre todo por el estructuralismo moderno. Este autor señala que, para que esto fuera así, el escritor tendría que poseer cierta conciencia de lo que está transcribiendo, es decir, de las estructuras lingüísticas que subyacen a lo oral, como son las palabras, las sílabas y los fonemas. Sin embargo, sólo aquellos sujetos alfabetizados son conscientes de estas estructuras, por lo que la concepción de la escritura como una mera transcripción no tiene sentido. Olson aboga por la concepción de la escritura como "modelo del habla», es decir, como una forma de representación del habla, distinta de ésta, que provee de categorías a partir de las cuales nos hacemos conscientes del lenguaje. Desde este punto de vista, Olson pretende aproximarse al 
problema de cómo la escritura se convierte en una tecnología de la mente, al ser capaz de traer a la conciencia las estructuras lingüísticas - patrones fonológicos, estructura gramatical y forma lógica-. Por otra parte, la adquisición de la escritura facilita el paso desde la comprensión de la necesidad de las relaciones en el mundo a la comprensión de esta misma necesidad entre proposiciones explícitas, es decir, a una comprensión metalógica, que va más allá de los sucesos concretos que se dan en el mundo. El medio escrito, por tanto, pone de manifiesto las propiedades lógicas del habla, ya que para que una premisa se siga de otra requiere un tipo particular de discurso, un discurso de significados literales, de textos cerrados, que es lo que aporta la escritura.

Sin embargo, desde otras perspectivas teóricas, la naturaleza de estas dos formas de lenguaje, la oral y la escrita, es idéntica y ambas representan un continuo evolutivo que hay que tener en cuenta para desarrollar un programa de alfabetización adecuado. A continuación exponemos un modelo teórico que concibe la alfabetización de forma muy distinta.

\section{LENGUAJE ORAL Y LENGUAJE ESCRITO: DOS CARAS DE UNA MISMA MONEDA}

Gran cantidad de autores conciben la alfabetización como el aprendizaje del lenguaje escrito. Sin embargo, vamos a presentar un enfoque en el que se incluye el lenguaje oral en este proceso. Garton y Pratt (1989), al comienzo de su libro, definen el aprendizaje de la alfabetización como «...el desarrollo del lenguaje oral y escrito desde sus orígenes en la temprana infancia basta el manejo de estos como sistemas de representación y comunicación con los otros.» (pag. 1). Como vemos, la principal diferencia que se plantea entre el modelo anteriormente expuesto y el de Garton y Pratt es la estrecha unión que establecen estas autoras entre el desarrollo del lenguaje oral y el escrito, por una parte, y la función específica que le asignan a este desarrollo, por otro.

En cuanto el primer punto, vemos que ellas no establecen un corte radical entre ambos tipos de lenguaje, sino que los consideran un continuo. La alfabetización sería el dominio tanto del lenguaje oral como de la lectura y la escritura. Estas autoras dan dos razones principales para tratar estos dos sistemas de lenguaje de forma conjunta:

1. Porque hay relaciones estrechas entre ellos, de forma que el desarrollo del lenguaje escrito está fuertemente ligado al del lenguaje oral, ya que es una adquisición de segundo orden basada en éste y, por su parte, la adquisición de la lecto-escritura provee al lenguaje oral de nuevas estructuras y funciones que son aprendidas dentro de este nuevo ámbito.

2. Porque el aprendizaje de la lectura y la escritura depende en gran medida del conocimiento previo que se posee sobre el lenguaje oral, y muchos de los procesos implicados en el aprendizaje del lenguaje oral y escrito son comunes, como por ejemplo la necesidad de apoyo en su evolución de un adulto o un igual más capaz.

Por otra parte, en cuanto a la función concreta que estas autoras asignan a la alfabetización, el manejo del lenguaje oral y escrito como sistemas de representación y comunicación con los otros, la diferencia principal con el modelo anterior es doble. En primer lugar, estas autoras consideran que la función de estas dos formas, oral y escrita, es común a lo largo de todo el desarrollo, y no hacen ninguna distinción entre ellas. Sin embargo, en el enfoque expuesto anteriormente, se piensa que una vez que se ha adquirido la capacidad de lecto-escritura, ésta se pone al servicio del pensamiento, cumpliendo así una función distinta a la comunicativa.

En segundo lugar, Garton y Pratt no plantean que el lenguaje escrito tenga una relación cualitativamente distinta que la que tiene el oral con el pensamiento, 
como se hace en el modelo anterior. Mientras que en el modelo «epistémico» tratado en el punto anterior, se piensa que el modo escrito posibilita la toma de conciencia de las estructuras subyacentes al lenguaje, estas autoras postulan un mecanismo independiente que cumple esta misión: la conciencia metalingüística. Definen este concepto como «...la habilidad para centrar la atención en el lenguaje y reflexionar sobre su naturaleza, estructura y funciones.» (pag. 126). Esta habilidad es central en el desarrollo del lenguaje y la alfabetización, y evoluciona de forma paralela. Para estas autoras, esta capacidad aparece tempranamente, fomentada en primer lugar por los errores en el habla, que el niño corrige deliberadamente, reflexionando sobre su producción lingüística, y en segundo lugar, por la toma de conciencia del mundo impreso que le rodea, y al que el niño intenta dar sentido desde sus primeros encuentros con éste.

En relación con este último punto, hay que mencionar que la interacción social es considerada al final del libro como el mecanismo de aprendizaje del lenguaje más importante, sobre todo porque contribuye a aumentar la conciencia metalinguística, y esta a su vez facilita la interacción comunicativa. Este argumento implica un papel activo del niño en el proceso de aprendizaje y un papel de apoyo externo del adulto. En esta interacción, lo importante es que el adulto sea sensible a las necesidades del niño, a sus logros, y que esté listo para ayudar y animar los esfuerzos del niño al hablar, escribir o leer.

Por otra parte, estas autoras mencionan dos ideas erróneas acerca del desarrollo del lenguaje, como son que el desarrollo del lenguaje oral esta completo cuando lo niños llegan a la escuela y, por otra parte, que éstos no saben nada acerca de la lectura y la escritura cuando comienzan la escolarización. Según Garton y Pratt, «lo que varia entre un niño y otro es la naturaleza de la experiencia y la medida en que tuvo la oportunidad de implicarse activamente. Además, hay que tener en cuenta que tanto el lenguaje oral como el escrito pueden fomentarse desde edades muy tempranas en la escuela primaria. Los componentes de la alfabetización, el lenguaje oral, el escrito y la lectura, están en continua interacción. No son adquisiciones evolutivas independientes, desconectadas unas de las otras, sino que el aprendizaje en una de ellas puede beneficiar a las demás.» (pag.220).

Pero, ¿cuáles son las consecuencias cognitivas que estas autoras asignan al proceso de alfabetización? Es en este punto donde este enfoque se separa claramente del anterior, ya que afirman que el aumento en las habilidades cognitivas que se pueda derivar de la alfabetización no se debe exclusivamente al aprendizaje de la lectoescritura, sino también al desarrollo y a la exposición al lenguaje oral. Según estas autoras, las conversaciones que tienen lugar en el aula dan lugar a formas diferentes de hablar sobre el mundo y pensar acerca de él, lo que da lugar a un incremento de las habilidades cognitivas y el conocimiento del niño. Este incremento se centra principalmente en la petición y obtención de información, mediante la formulación de preguntas en el lenguaje oral y la lectura en el lenguaje escrito. Por otra parte, no hablan de una influencia cualitativamente distinta de las habilidades de lecto-escritura en el pensamiento, formando estas parte del continuo oral-escrito.

\section{¿QUÉ ES LA ALFABETIZACIÓN PARA EL LENGUAJE INTEGRADO?}

A continuación expondremos las ideas que maneja el lenguaje integrado acerca del proceso de alfabetización, contrastándolas con las de los dos modelos expuestos anteriormente.

¿Cuales son las diferencias entre estos dos modelos? Principalmente, en el primero se piensa que la adquisición de la lecto-escritura, a la que se considera, además de como un código distinto, como una nueva forma de lenguaje, dota al sujeto de un instrumento cognitivo que posibilitará el paso de una conciencia situacional, ligada 
a lo concreto, a una conciencia fuera de contexto, que le permitirá la elaboración de abstracciones. Sin embargo, en el segundo modelo, la alfabetización abarcaría la totalidad del lenguaje en todas sus formas -oral y escrita - cuyo desarrollo sería común y su naturaleza idéntica. Estos dos modelos coinciden con las dos teorías sobre el desarrollo del lenguaje expuestas por Stotsky (1987). Según la primera teoría (ligada al segundo modelo expuesto anteriormente), las estructuras de la experiencia del lenguaje oral influyen en la lectura y la escritura en todos los niveles del desarrollo de la alfabetización. Es más, el lenguaje escrito no se considera distinto del oral. Esta autora cita un comentario de Smith (1975), que ejemplifica de forma clara esta concepción: «El lenguaje oral y escrito... son formas estructurales superficiales alternativas de un lenguaje subyacente común». Es decir, «la sustancia y la estructura del lenguaje escrito no se diferencia de la sustancia y la estructura del lenguaje oral.» (pag.372). Si, como afirma esta teoría, el lenguaje escrito no es cualitativamente distinto del oral, los problemas de comprensión y composición serían los mismos para el lector y el escritor y para el hablante y el receptor. La implicación pedagógica de este postulado sería que no hace falta ningún esfuerzo adicional dirigido a la lecto-escritura, ya que ésta no plantearía problemas a ningún nivel evolutivo que no se puedan solucionar a través de la práctica oral. Los partidarios de esta teoría ponen, por tanto, énfasis en la interacción social como método para alfabetizar, y en el desarrollo de una base sólida de lenguaje oral. Se basan en el enriquecimiento del lenguaje natural por medio de variadas actividades orales junto con experiencias prácticas.

Stotsky (1970) menciona como autores asociados a la segunda teoría, a la que da el nombre de «epistémica», a Vygotsky, Bruner, Luria y Simon. Según este último autor, «el lenguaje escrito no surge como un "gemelo" del oral; ambos pueden compartir ciertos elementos, pero precisan de recursos distintos para su desarrollo, y usan medios distintos para conseguir distintas metas» (pag.378). Por lo tanto, según esta teoría, el lenguaje oral y el escrito tienen orígenes y propósitos distintos, y su naturaleza es cualitativamente diferente. Según Stotsky, "la escritura, aunque al principio depende del lenguaje oral basta que los alumnos aprenden a decodificar y codificar, se bace cada vez más independiente de éste y mas dependiente de sí mismo» (pag. 378). Por lo tanto, una implicación pedagógica importante es que la instrucción de la lecto-escritura debe basarse en la exposición al lenguaje escrito. Los profesores deben exponer regularmente a niveles cada vez más altos de densidad textual, y el currículum debe estar cuidadosamente planificado. También deben exponer a sus alumnos a una práctica regular en escritura. Aunque se utilicen experiencias orales, estas no sustituyen en ningún momento a las de lectura y escritura.

¿Dónde se sirúa el lenguaje integrado con respecto a estas dos teorías del desarrollo del lenguaje y la alfabetización? El postulado esencial de este movimiento es que la naturaleza que subyace al lenguaje oral y escrito es idéntica, lo cual liga al lenguaje integrado con la primera teoría de la que habla Stotsky y el segundo modelo expuesto en este artículo. Para los seguidores del lenguaje integrado, el desarrollo de ambas formas lingüísticas se produce en un continuo evolutivo que comienza cuando el niño entra en contacto con el lenguaje, tanto oral como escrito, de forma natural. Es esencial para la práctica pedagógica que desarrolla este movimiento la idea de que el aprendizaje del lenguaje escrito comienza mucho antes de que el niño llegue a la escuela, y, por lo tanto, antes de la adquisición de las habilidades grafomotoras. Cuando el niño llega a la escuela, lo hace con un conjunto importante de conocimientos sobre el mundo impreso que le permiten dar y construir significado a partir de la escritura. El maestro que trabaja bajo esta perspectiva utilizará este conocimiento previo como base esencial para la instrucción.

Varias son las características del lenguaje integrado que se derivan de su postulado principal: 
1. En primer lugar, ya que ambos modos de lenguaje, oral y escrito, poseen la misma naturaleza, los mecanismos de aprendizaje para ambos procesos serán los mismos. Por lo tanto, el niño aprende a leer y a escribir óptimamente bajo condiciones similares a aquellas bajo las que se aprende a hablar, a partir del todo hacia las partes en contextos significativos y naturales.

2. En segundo lugar, el considerar el lenguaje como un proceso unitario en cualquiera de sus formas, les lleva a concluir que cualquier avance que se produzca en una modalidad repercutirá en todas las demás. Según Goodman, Smith, Meredith y Goodman (1987), leer, escribir, hablar y escuchar están basados en principios y procesos similares. Leigh (1980) critica los métodos de enseñanza tradicionales que mantienen separados estos aspectos del lenguaje, y la suposición de que la expresión y comprensión oral ya se dominan al llegar a la escuela. El lenguaje integrado intenta desarrollar las habilidades lingüísticas aprovechando las relaciones naturales que existen entre todos los componentes.

3. Los seguidores de este movimiento conceden gran importancia a la relación entre la función del lenguaje y su aprendizaje e instrucción. Para ellos, ya que la función principal de todo proceso lingüístico es la construcción del significado para su transmisión a otros, este debe ser aprendido en contextos significativos en el que el niño utilice el lenguaje con propósitos específicos y reales. Según Leigh (1980), el lenguaje, en todas sus formas, implica un proceso interactivo en contextos sociales. La finalidad esencial del lenguaje, tanto oral como escrito, es facilitar que el hablante y el que escucha o el lector y el escritor compartan significados. Para el lenguaje integrado, el desarrollo del lenguaje debe darse a través de interacciones significativas entre la gente, a través de su uso funcional en experiencias diarias (Goodman y Goodman, 1976). Podríamos aceptar la siguiente definición que está presente en quienes trabajan desde esta perspectiva «... Un nuevo término para la instructión de la alfabetización que bace bincapié en la aplicación de la lectura y la escritura en contextos significativos.»

Por otra parte, el niño es considerado como un comunicador con un deseo natural de compartir ideas, información y sentimientos con otros. Por lo tanto, el ambiente ideal para alfabetizar es un contexto consistente que permita al niño usar sus nuevas habilidades de una forma significativa. El uso del lenguaje siempre se da en una situación determinada, por lo que las situaciones son críticas para la construcción del significado (Altwerber $e t$ al., 1987)

4. Si todos los sistemas lingüísticos se dan unidos en cada uso del lenguaje, no tendrá sentido la instrucción de habilidades lingüísticas separadas, sino que estas deben ser tratadas como un todo que evoluciona simultáneamente en cada situación educativa. En este sentido, no sería necesario ni conveniente descomponer las habilidades de lecto-escritura en subhabilidades, sino que estas deben de ser comprendidas como herramientas para mejorar la calidad de la lectura y la escritura como un todo.

Por lo tanto, el lenguaje no se debe enseñar de forma fragmentada, sino holística (Goodman, Smith, Meredith y Goodman, 1987). Según Altwerberg y sus colaboradores, los distintos sistemas del lenguaje (fonología en lo oral, ortografía en lo escrito, morfología, sintaxis, semántica y pragmática) están presentes simultáneamente e interactúan en todo uso del lenguaje. Por lo tanto, no tendrá sentido fragmentarlo en las situaciones educativas.

El problema principal que observamos en las creencias que sobre alfabetización que subyacen al lenguaje integrado es que las evidencias empíricas en las que se basan son escasas, sobre todo en lo referente a la afirmación de que los procesos de aprendizaje son los mismos para lo oral y para lo escrito. Esta cuestión no debe pasarse por alto, ya que estas creencias, de ser ciertas, cambiarían profundamente los métodos de alfabetización. 
Analicemos el siguiente párrafo, escrito por Giddings (1992): «Los investigadores que ban estudiado los procesos cognitivos de los lectores afirman que, en el acto de la lectura, éstos son capaces de comprender la estructura de la bistoria, hacen inferencias sobre los pasajes con el fin de construir significado y utilizan su propio conocimiento en la buisqueda del significado de los textos. Proponen que la lectura verdadera comienza con la buisqueda por parte del lector del conocimiento y el significado. Las palabras individuales en la página se reconocen sólo para facilitar la comprensión. Smith (1988) aclara esta posición cuando explica que los niños aprenden a leer igual que aprenden a bablar, generando y evaluando bipótesis sobre los materiales de lectura y recibiendo una retroalimentación adecuada."

¿Qué tiene de erróneo este razonamiento? En primer lugar, las investigaciones de las que habla este autor se refieren, en su gran mayoría, a estudios llevados a cabo con sujetos alfabetizados, que poseen ya las habilidades de decodificación en la lectura. Sin embargo, Giddings extrapola estas afirmaciones al campo del aprendizaje de la lectura, en el que el individuo no ha adquirido aún estas habilidades. Su razonamiento es el siguiente: el lenguaje escrito es de la misma naturaleza que el oral, por lo tanto, el proceso de aprendizaje debe ser similar; la práctica pedagógica en la enseñanza de la lecto-escritura debe reproducir situaciones en las que aparezcan los mismos elementos que se dan en las situaciones de aprendizaje del lenguaje oral. El elemento más importante que se da en estas situaciones es que el lenguaje se da en contextos significativos y en interacción con otros usuarios del lenguaje. Por lo tanto, no será necesario enseñar a leer y a escribir directamente, sino que basta con exponer al niño a situaciones significativas con material impreso real.

Pero ¿en qué se basa este autor para mantener estas creencias? La base de esta perspectiva es, como hemos mencionado anteriormente, que el lenguaje oral y el escrito son dos caras de la misma moneda, lo cual le asocia a la primera teoría mencionada por Stotsky. Esta autora nos muestra que, a pesar de que hay evidencia empírica que apoya tanto la primera como la segunda teoría, la referente a la primera es inconsistente.

Es importante, como hemos mencionado al principio, que las creencias que subyacen a una perspectiva educativa estén apoyadas por los datos resultantes de una investigación sistemática acerca de los procesos a los que va dirigida dicha perspectiva, y sus mecanismos específicos de aprendizaje. Thompson (1992) critica la filosofía y la metodología del lenguaje integrado, y sobre todo su presupuesto de que los niños aprenderán a leer y escribir simplemente leyendo y escribiendo con una instrucción incidental de sus profesores. Este autor menciona el trabajo de Stahl y Miller (1989), en el que analizan hallazgos experimentales que indican que el lenguaje integrado es menos efectivo que otros métodos con los niños desaventajados o de capas sociales más bajas, y el de Adams (1990), que pone de manifiesto que es necesaria la enseñanza del principio alfabético en la instrucción de la lecto-escritura en edades tempranas.

Como puntos a favor del lenguaje integrado, podemos mencionar la enseñanza del lenguaje en situaciones significativas, de gran utilidad e importancia, así como el uso de textos reales y la construcción del conocimiento sobre una base ya adquirida por el niño previamente; sin embargo, la afirmación de que la instrucción de la lecto-escritura no precisa una enseñanza de ciertos aspectos ligados al código en sí mismo debe ser contrastada de una forma más precisa.

\section{Referencias}

ADAMS, M. J. (1990). Beginning to read: Thinking and learning about print. Cambridge, MA: The MIT Press.

ALTWERGER; EDELSKY, y FLORES (1987). Whole language: What's new?. The Reading Teacher, 41, 144-154. 
FraNCIS, H. (1987) Cognitive implications of learning to read. Interchange, 18, 97-108.

GARTON, A., y PRATT, C. (1989). Leaming to be litetate: The development of spoken \& uritten language. Blackwell Publishers: Oxford.

GIDDINGS, L. R. (1992). Literature-based reading instruction: An analysis. Reading Research and Instruction, 31 (2), 18-30.

Goodman, K. S., y Goodman, Y. M.(1976). Learning to read is natura. Paper presented at the Conference on Theory and Practice of Beginning Reading Instruction: Pittsburgh, P.A.

GoOdMAN, K. S; SMITH, E. B.; MeredITH, R., y GOODMAN, Y. M. (1987). Language and Thinking in School: A Whole Language Curriculum (3rd. ed.). Nueva York: Richard C. Owens.

HARSTE, J. C., y BuRKE, C. L. (1989). Examining instructional assumptions: The child as informant. En Manning, G. y Manning, M. (Eds.). Whole language: Beliefs and practices, $K-8$. National Education Association: Washington, D. C.

LEIGH, J. E. (1980). Whole language approaches: Premises and possibilities. Learning Disability Quarterly, 3, 62-69.

Newman, J. M. (1985). Whole language. Theory inuse (pp. 7-36). Portsmourh, NH: Heinemann

OLSON, D. R. (1993). Writing, literal meaning, and logical proof. En Scholes, R.J . (Ed.), Literacy and language analysis. L.E.A., Publishers.

Simon, J.(1970). Evolution génétique de la pbrase écrite chez l'écolier. Tesis doctoral no publicada, Universidad de París.

SMITH, F.(1975). The relations between spoken and written language. En Lenneberg, E.H. y Lenneberg, E. (Eds.), Foundations of Language Development: A Multidisciplinary Approach (Vol.2). Academic Press: Nueva York.

STAHL y MLLLER (1989). Whole language and language experience approaches for beginning reading: A quantitative research synthesis. Review of Educational Research, 50 (1), 87-117.

STOTSKY, S. (1987). A comparison of the two theories about development in written language: Implications for Pedagogy and research. En Horowitz, R. y Samuels, S.J. (Eds.). Comprebending oral and written language. Academic Press, INC.

THOMPSON, R. A. (1992). A critical perspective on whole language. An international quarterly, 13, 131-155.

W ATSON, D. J. (1989). Defining and describing whole language. The Elementary School Journal, 90, 129-141.

WELL, G. (1987). Apprenticeship in Literacy. Intercbange, 18, (1/2), 109-123.

\section{Lenguaje integrado: sus creencias sobre la alfabetización \\ Beatriz Martín \\ CL\&E, 1995, 25, pp. 21-29}

Resumen: Este artículo revisa las implicaciones que tiene para la enseñanza de la lecto-escritura aceptar un modelo teórico u otro acerca de la naturaleza del lenguaje. Los autores que adoptan el enfoque del lenguaje integrado presuponen una naturaleza holista del lenguaje y, tomando como punto de partida el modo en que los niños aprenden la lengua materna, consideran que la lengua oral y escrita se enseñan y aprenden de la misma manera: simplemente a través de la práctica. El artículo hace un análisis crítico de estas ideas y propone alternativas.

Datos sobre el autor: Beatriz Matín del Campo es Licenciada en Psicología por la Universidad Autónoma de Madrrid. Actualmente es becaria del Plan de Formación de Personal Docente e Investigador de la U.N.E.D. Trabaja en temas relacionados con e desarrollo de la lengua escrita, le interesa especialmente el tema de los formatos textuales.

Dirección: Departamento de Psicología Evolutiva y de la Educación. Facultad de Psicología. U.N.E.D. Ciudad Universitaria s/n. 28040 Madrid. Fax: 913986216.

C PERMISOS PARA CITAR O REPRODUCIR EN OTRAS FUENTES: Se pueden citar libremente hasta 500 palabras. Para reproducir una porción de texto mayor, figuras o ilustraciones, se deberá pedir permiso por escrito a la revista, especificando el uso al que se destina el texto. En todos los casos, se deberá citar el copyright de $C L \& E$. En el caso de artículos o textos que hayan sido a su vez reproducidos en $C L \& E$ los interesados deberán dirigirse tanto a los detentadores del copyright original como a $C L \& E$, en el caso de que se quiera hacer uso de la traducción. FOTOCOPIAS: Para todo lo relacionado con el uso mediante fotocopia del material de esta revista, deberán dirigirse a: CEDRO, C/ José Marañón, 10, $3 .^{\circ}$ Izda. Tel. 5941575 . Fax 4453567 